CBIE-LACLO 2015

Anais dos Workshops do IV Congresso Brasileiro de Informática na Educação (CBIE 2015)

\title{
Uma Experiência Piloto de Integração Curricular do Raciocínio Computacional na Educação Básica
}

\author{
Fernando Paiva ${ }^{1}$, Ana Carolina Ferreira ${ }^{1}$, Caio Rocha ${ }^{1}$, Jandiaci Barreto ${ }^{2}$, Randerson \\ Haine Lopes ${ }^{3}$, André Melhor'1, Ecivaldo Matos ${ }^{1}$ \\ ${ }^{1}$ Instituto de Matemática - Departamento de Ciência da Computação; ${ }^{2}$ Instituto de Letras; \\ ${ }^{3}$ Instituto de Humanidades, Artes e Ciências Professor Milton Santos \\ Universidade Federal da Bahia (UFBA) \\ Avenida Adhemar de Barros, s/n - CEP 40170-110 - Salvador - BA - Brasil \\ \{lfp.fernandopaiva, anacarolina.cfl, cw.rocha7, jandiacy, hainelopes, \\ andremelhor\}@gmail.com, ecivaldo@ufba.br
}

Resumo. Neste artigo é descrita uma iniciativa de integração curricular do raciocínio computacional aos conteúdos disciplinares da educação básica (ensino fundamental e médio) em uma escola pública estadual por meio da computação desplugada, apresentando a possibilidade de forma metodológica da construção interdisciplinar e, fundamentalmente, dialógica dos conteúdos da Ciência da Computação incorporando-os às disciplinas escolares regulares.

\section{Introdução}

No campo da educação escolar, busca-se articulação conceitual e prática entre a Ciência da Computação (CC) e as disciplinas escolares, como uma possibilidade de relação entre os conteúdos curriculares e conhecimentos da CC. A Ciência da Computação é uma área de conhecimento que pelo seu inerente caráter universal e mediatizador, permite um leque de possibilidades para a realização de conexões interdisciplinares, tanto para a sua evolução enquanto ciência, quanto para a sua aplicação na resolução de problemas mais complexos. Esses problemas podem ser explorados por meio da interdisciplinaridade (Cassel, 2011).

A construção de práticas de ensino contextualizadas direciona para uma perspectiva interdisciplinar. Isso permite vislumbrar novos modelos de currículos híbridos, rompendo com a ideia de pureza epistemológica, tendo em vista as novas ideias que podem advir a partir das inter-relações, oferecendo oportunidades, riscos, ambivalências e possibilidades de construção de políticas e práticas curriculares, numa perspectiva voltada para a mudança social, como aponta Matos e Paiva (2007).

Atualmente as possibilidades de conexões interdisciplinares e a contextualização são uma necessidade constante em todo o currículo (prescrito), como apontam os Parâmetros Curriculares Nacionais (PCN) e as Diretrizes Curriculares Nacionais da Educação Básica. Além disso, a complexidade do cotidiano exige que os estudantes sejam formados com habilidade para lidar com problemas complexos e de diferentes naturezas. Lopes (2005) explica que o currículo tem se caracterizado por um hibridismo de tendências teóricas diferentes. Portanto, relacionar CC às disciplinas escolares de modo interdisciplinar está de acordo com políticas que favorecem a heterogeneidade do currículo.

Lopes (2005) aponta que as políticas de currículo de outros países parecem ter contribuído para ampliar as pesquisas educacionais nacionais. $\mathrm{Na}$ busca por novas metodologias fazendo uma mixagem das concepções tradicionais com as novas concepções, 
o currículo escolar brasileiro tem sofrido reinterpretações contextuais, mostrando-se como um currículo recontextualizado por hibridismo. A autora também apresenta a necessidade de investigar políticas educacionais considerando as articulações e reinterpretações em múltiplos contextos das influências internacionais nas práticas escolares.

Logo, o desenvolvimento de projetos educacionais interdisciplinares que explorem as relações entre os diversos componentes curriculares têm sido importantes para o desenvolvimento cognitivo dos estudantes, ressalta Matos (2013). Isso implica que nosso campo de trabalho está pautado em um currículo integrado, onde o objetivo é procurar relações em todas as direções. Considerando-se a integração curricular como "um modo de estabelecer inter-relações a partir de problemas e temas comuns das disciplinas de referência, valorizando a lógica da disciplinaridade e, ao mesmo tempo, a articulação entre os conhecimentos especificos de cada disciplina” (Matos, 2013 p. 26).

Nesse sentido, Fortes (2009, p. 4) explica que “[...] interdisciplinaridade é estabelecer ligações de complementaridade, convergência, interconexões e passagens entre os conhecimentos", e ações de integração curricular realizadas interdisciplinarmente por meio da CC podem favorecer a perspectiva do desenvolvimento de uma nova habilidade: o raciocínio computacional. Ribeiro et al. (2013) explicam que sem diretrizes claras sobre o que deve ser ensinado e quando isso deve acontecer, torna-se muito difícil incluir com sucesso o raciocínio computacional no currículo da maioria das escolas brasileiras.

Uma das possibilidades de articulação curricular do raciocínio computacional nas escolas pode ser a Computação Desplugada, técnica desenvolvida por Tim Bell, Lan H. Witten e Mike Fellows que tem o objetivo de ensinar fundamentos de computação com atividades sem uso de computadores (Bell et al. 2009). A Computação Desplugada apresentase como uma alternativa para a execução de atividades que estimulam o raciocínio computacional sem o uso de computadores ou quaisquer outros recursos eletroeletrônicos, adequando-se melhor em espaços em que a infraestrutura tecnológica de computação é deficiente ou ausente; algo bastante comum nas escolas públicas brasileiras.

Há outras iniciativas conhecidas mundialmente que procuram desenvolver o raciocínio computacional nos primeiros anos escolares. Algumas dessas iniciativas possuem apoio de educadores, organizações governamentais, indústria e organizações sem fins lucrativos. Uma delas é a Computer Science Teachers Association- CSTA ${ }^{1}$, organização que apoia e promove o ensino de $\mathrm{CC}$ e outras disciplinas de computação no currículo $\mathrm{K}-12$ dos Estados Unidos, equivalente ao ensino fundamental e médio brasileiro. A International Society for Technology in Education - ISTE ${ }^{2}$, defende a tecnologia na sala de aula por meio de recursos digitais com o objetivo de apoiar o ensino e a aprendizagem.

A crescente demanda de pesquisas sobre ensino e aprendizagem de Computação está abrindo um nicho no mercado de aplicativos e sistemas com o objetivo de ensinar o raciocínio computacional. Grandes empresas como Microsoft e Google também estão engajadas em desenvolver esse raciocínio, principalmente nos primeiros anos escolares. A Microsoft desenvolveu um ambiente integrado chamado $\mathrm{Kodu}^{3}$, direcionada para crianças com o objetivo de ensinar programação com uma linguagem visual. A Google, por sua vez, está

\footnotetext{
${ }^{1}<$ www.csta.acm.org/>

${ }^{2}<$ www.iste.org/>

${ }^{3}<$ www.kodugamelab.com/>
} 
promovendo um curso para educadores chamado Computational Thinking for Educators ${ }^{4}$, com o objetivo desenvolver uma consciência entre os educadores de todo o mundo e incentivá-los a integrar raciocínio computacional em seus currículos.

Nesse sentido, este trabalho relata uma experiência de aplicação interdisciplinar da Computação Desplugada em uma escola pública de referência do município de Salvador BA, como etapa-piloto de uma investigação científica acerca do diálogo intersemiótico entre a $\mathrm{CC}$ e as disciplinas escolares regulares.

No restante do trabalho serão detalhados tais aspectos da seguinte forma: na seção 2 se estabelece uma discussão teórica acerca das definições de raciocínio computacional e alguns trabalhos relacionados; na seção 3 é apresentado um breve detalhamento das intervenções que foram realizadas; na seção 4 é exposta uma avaliação das intervenções a partir dos dados coletados por meio de um grupo focal realizado com os professores que participaram das intervenções; na seção 5 são tratadas as conclusões da pesquisa e apresentados os próximos passos do projeto.

\section{Raciocínio ou Pensamento Computacional? - Dosado com interdisciplinaridade}

A disseminação do raciocínio computacional, por meio do pensamento computacional, vem crescendo entre os estudos relacionados ao ensino da CC. Por isso faz-se necessário estabelecer uma breve discussão acerca desses conceitos, para que possamos utilizá-los adequadamente. A diferenciação conceitual entre raciocínio computacional e pensamento computacional não está apenas nos termos utilizados, mas sobretudo nas diferenciadas compreensões acerca do tema.

Segundo Japiassú e Marcondes (1993) pensamento é uma "atividade da mente através da qual esta tematiza objetos ou toma decisões sobre a realização de uma ação.” (p. 209). Segundo os mesmos autores, raciocínio é uma "atividade do pensamento pela qual se procede a um encadeamento de juízos visando estabelecer a verdade ou a falsidade de algo. Procedimento racional de argumentação ou de justificação de uma hipótese” (id, p. 228).

Segundo Wing (2006, p. 33-35),

Computational thinking é uma habilidade fundamental para todos, não apenas para cientistas da computação. [...] inclui uma variedade de ferramentas mentais que refletem a largura do campo da ciência da computação. [...] é usado no raciocínio heurístico para descobrir uma solução. [...] Computational thinking é uma grande visão para orientar os educadores de ciência da computação, pesquisadores e praticantes como agimos para mudar a imagem do campo da sociedade. (tradução e grifo nossos)

Como podemos ver, a autora apresenta o que chama de computational thinking, como um conjunto de ferramentas mentais usado para raciocínio heurístico (no cotidiano, para além dos cientistas). A tradução livre de interpretação, reduz o conceito explicado por Wing ao senso comum. Neste artigo preferimos utilizar a expressão "raciocínio computacional", por considerá-lo mais adequado ao que de fato reconhecemos como computational thinking.

Wing (2006) ao trazer algum exemplo explicando o que seria pensamento

\footnotetext{
${ }^{4}<$ computationalthinkingcourse.withgoogle.com>
} 
CBIE-LACLO 2015

Anais dos Workshops do IV Congresso Brasileiro de Informática na Educação (CBIE 2015)

computacional, faz uso do termo "raciocínio" para citar algo específico da CC. A maioria dos autores que utilizam sua obra como base seguem a mesma ideia, como podemos ver em Ribeiro et al. (2013), quando apresentam um exemplo onde explica de forma detalhada a aplicação do algoritmo no cotidiano:

Os estudos de algoritmos envolvem conceitos como abstração, refinamento, a modularização, recursão, etc. Aprender esses conceitos melhora a capacidade de raciocínio e resolução de problemas por meio de processos de aprendizagem meta-cognitiva, considerado essencial para a inteligência.[...] Para ilustrar esta ideia, podemos pensar em um cenário computacional consiste em uma pessoa A, com sua linguagem LA, uma pessoa $B$, com sua linguagem $L B$, e uma máquina $M$ (um computador, por exemplo) com o seu LM idioma. A recebe um problema $P$ para resolver (por exemplo, para extrair a raiz quadrada de um número). Depois de analisar o problema, A escolhe uma máquina, por exemplo $M$, em que a solução pode ser adequadamente aplicado. A solução é então escrita numa linguagem LM compreensível pela máquina M. A solução do problema é conhecido como algoritmo. $O$ processo de resolução de problemas (envolvendo análise de problemas, selecionando máquinas adequadas, construção e algoritmos de execução) é chamado pensamento computacional. (p. 22-23) (tradução nossa)

Podemos compreender que esse processo específico de resolução de um problema seria o raciocínio computacional, pois essas características apresentadas fazem parte do pensamento analítico, que consequentemente faz parte do pensamento computacional. Portanto, neste texto, consideramos que ao tratar sobre pensamento computacional, o que estão sendo envolvidos de fato são os mecanismos e elementos epistemológicos de raciocínio computacional. Esse raciocínio se expressa quando o pensamento computacional está relacionado ao pensamento analítico e ao raciocínio inferencial (abdutivo, indutivo ou dedutivo) - com envolvimento da lógica e/ou da matemática. Dessa forma, podemos assimilar o raciocínio computacional como a capacidade de resolução de problemas de forma sistemática, usando inferências lógicas e abstrações, habilidades importantes para a CC.

Na literatura sobre Educação em Computação mais recente, há diversos trabalhos sobre raciocínio computacional. Carvalho et al. (2013), apresentam por exemplo trabalhos realizados em diferentes países. Também mostra que há várias iniciativas como Howell et al. (2011), que descreve a primeira fase de um projeto multidisciplinar entre os professores de computação e língua inglesa. Apresenta também, a inserção imediata de conceitos de raciocínio computacional às escolas de ensino médio do estado do Alabama, EUA (Jenkins et al. 2012). Assim como no Brasil, nos Estados Unidos esse não é um tema novo, alguns resultados já estão consolidados e foram apresentados pela CSTA.

$\mathrm{Na}$ área de Computação, algumas práticas interdisciplinares isoladas já têm sido realizadas, como aquelas que descrevem experiências de integração curricular envolvendo resolução de problemas no ensino superior (Pinto et al., 2010; Matos, 2013). Todavia, poucos são os relatos e/ou estudos de experiências interdisciplinares de integração curricular envolvendo a CC na educação básica. França et al. (2014) apresentam em seu trabalho a importância do ensino dos fundamentos da CC com outras áreas no intuito de disseminar o pensamento computacional na educação básica e pontua a promoção do pensamento computacional de modo interdisciplinar, ressaltando que "a interdisciplinaridade do pensamento computacional também tem sido considerada em ações que exacerbam a 
CBIE-LACLO 2015

Anais dos Workshops do IV Congresso Brasileiro de Informática na Educação (CBIE 2015)

necessidade de conhecimentos em Computação, na educação básica." (França et al., 2014, p. 1510).

\section{Metodologia de Desenvolvimento das Intervenções}

A escola sede das intervenções está localizada em um bairro da periferia do município de Salvador - BA; a unidade escolar possui atualmente 985 estudantes na educação fundamental $\left(1^{\circ}\right.$ e $2^{\circ}$ ciclos $)$ e 366 estudantes no ensino médio. Foram realizadas as intervenções descritas adiante e apresentadas em Ferreira et al (2015), onde encontra-se cada uma das intervenções desenvolvidas de forma detalhada, de acordo com o Quadro 1. Esse quadro apresenta resumidamente as séries, disciplinas e seus conteúdos, os conteúdos de CC que foram trabalhos e um resumo de cada intervenção. A aplicação das atividades em cada disciplina/turma foi planejada e acompanhada pelo professor responsável pela disciplina/turma, totalizando sete professores.

Quadro 1: Resumo das Intervenções que foram aplicadas relacionada a cada série, disciplina e conteúdo

\begin{tabular}{|c|c|c|c|c|c|}
\hline & Disciplina & $\begin{array}{l}\text { Contel } \\
\text { Disci }\end{array}$ & $\begin{array}{l}\text { Conteúdo de } \\
\text { Computação }\end{array}$ & Série & $\begin{array}{c}\text { Raciocínio Computacional } \\
\text { Envolvido }\end{array}$ \\
\hline \multirow{2}{*}{ 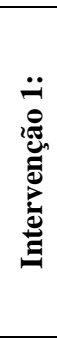 } & Artes & Dança Regional & $\begin{array}{l}\text { Algoritmos de } \\
\text { Ordenação }\end{array}$ & $1^{\circ}$ ano & $\begin{array}{l}\text { Criação de uma série ordenada de } \\
\text { instruções para resolver problemas } \\
\text { semelhantes, ou para fazer uma } \\
\text { tarefa. }\end{array}$ \\
\hline & \multicolumn{5}{|c|}{$\begin{array}{l}\text { Utilizando como recurso as danças regionais da Bahia, os alunos reproduziram alguns tipos de algoritmos de } \\
\text { ordenação e classificação, seguindo o ritmo da dança e utilizando uma coreografia - no caso, a lógica por trás } \\
\text { de cada algoritmo. Com o objetivo de ensinar como funciona a ordenação dos dados no computador, por meio } \\
\text { da dança, a equipe baseou-se no vídeo que envolve a dança folclórica húngara realizada pelo projeto } \\
\text { AlgoRythmics da Sapientia University, Targu Mures - Romênia }\end{array}$} \\
\hline \multirow{2}{*}{ 总 } & $\begin{array}{l}\text { Biologia } \\
\stackrel{+}{\text { Química }}\end{array}$ & $\begin{array}{l}\text { Equilíbrio Ecológico, } \\
\text { Cadeia Alimentar e } \\
\text { Balanceamento de } \\
\text { Equações químicas }\end{array}$ & $\begin{array}{l}\text { A Definição de } \\
\text { Algoritmos }\end{array}$ & $3^{\circ}$ ano & $\begin{array}{l}\text { Desenvolvimento de instruções } \\
\text { para solucionar um problema ou } \\
\text { etapas para uma tarefa. }\end{array}$ \\
\hline & \multicolumn{5}{|c|}{$\begin{array}{l}\text { Correlativo ao desequilíbrio ecológico (que ocorre quando existe alguma desarmonia na cadeia alimentar) } \\
\text { ao desequilíbrio químico, foi problematizado a necessidade de uma sequência ordenada de passos para se } \\
\text { resolver um determinado problema. Feito isso, lançou-se um problema de desequilíbrio ecológico que deveria } \\
\text { ser resolvido por meio do balanceamento de uma equação. Em seguida foi apresentado o processo de resolução } \\
\text { dessa equação como um algoritmo, pois segue uma sequência lógica de passos. O desafio dos alunos foi } \\
\text { descrever esses passos, ou seja, escrever um algoritmo }\end{array}$} \\
\hline \multirow{2}{*}{ 晜 } & $\begin{array}{l}\text { Educação } \\
\text { Física }\end{array}$ & $\begin{array}{l}\text { Movimentos } \\
\text { Corporais }\end{array}$ & $\begin{array}{c}\text { Lógica } \\
\text { Proposicional }\end{array}$ & $1^{\circ}$ ano & $\begin{array}{l}\text { Representação de dados por meio } \\
\text { da abstração com modelos e } \\
\text { simulações. }\end{array}$ \\
\hline & \multicolumn{5}{|c|}{$\begin{array}{l}\text { Utilizando "semáforos" com faces verde e vermelha e impressos com os conectores lógicos ("e", "ou”, "não } \\
\text { e" e "não ou"), com o objetivo de apresentar alguns dos elementos da lógica proposicional. Foram criadas } \\
\text { regras de travessia com base na associação de significados dos conectivos lógicos, desenvolvendo uma } \\
\text { introdução ingênua à construção de tabelas-verdade. O que estava em exercício era a velocidade de pensar e } \\
\text { se movimentar, justificando a sua interrelação com a Educação Física. }\end{array}$} \\
\hline \multirow{2}{*}{ 㟒 } & $\begin{array}{c}\text { Matemática + } \\
\text { Química }\end{array}$ & Logaritmos e $\mathrm{pH}$ & $\begin{array}{c}\text { Busca Sequencial } \\
\text { e Binária }\end{array}$ & $1^{\circ}$ ano & $\begin{array}{l}\text { Composição e decomposição para } \\
\text { tratamento de uma grande } \\
\text { quantidade de dados. Implica em } \\
\text { quebrar um problema em partes ou } \\
\text { etapas. }\end{array}$ \\
\hline & \multicolumn{5}{|c|}{$\begin{array}{l}\text { Os estudantes foram desafiados a descobrir o pH de algumas substâncias do dia-a-dia por meio da operação } \\
\text { logarítmica, e depois reproduziram e discutiram formas de realizar uma busca de valores dentro de um } \\
\text { conjunto. A atividade apresentou como alguns métodos de algoritmos busca trabalham. Para isto, utilizamos } \\
\text { placas com os valores de } \mathrm{pH} \text { de algumas substâncias, dando apenas a concentração da hidroxila (H+) de forma }\end{array}$} \\
\hline
\end{tabular}


CBIE-LACLO 2015

Anais dos Workshops do IV Congresso Brasileiro de Informática na Educação (CBIE 2015)

\begin{tabular}{|c|c|c|c|c|c|}
\hline & \multicolumn{5}{|c|}{$\begin{array}{l}\text { logarítmica. Após a comparação entre os dois métodos, foi realizado uma discussão se há uma forma melhor } \\
\text { de se realizar buscas dentro de um conjunto. }\end{array}$} \\
\hline \multirow{2}{*}{ 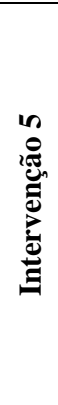 } & Matemática & Unidades de Medida & $\begin{array}{l}\text { Algoritmos como } \\
\text { uma sequência de } \\
\text { passos e com } \\
\text { múltiplas } \\
\text { soluções }\end{array}$ & $9^{\circ}$ ano & $\begin{array}{l}\text { Identificação, analise } \\
\text { implementação de soluções } \\
\text { possíveis com o objetivo de } \\
\text { alcançar a combinação mais } \\
\text { eficiente e eficaz de medidas e de } \\
\text { recursos. }\end{array}$ \\
\hline & \multicolumn{5}{|c|}{$\begin{array}{l}\text { Os estudantes nessa atividade deveriam movimentar um determinado volume de líquidos entre três recipientes } \\
\text { de capacidades distintas, até que eles ficassem igualmente distribuídos, utilizando o menor número de } \\
\text { movimentos. Ao final, ocorreu uma discussão sobre o conceito de algoritmo, o aluno pôde perceber que } \\
\text { existem diferentes meios distintos de se resolver o mesmo problema e entre eles o melhor: aquele que utiliza } \\
\text { uma quantidade menor de passos possível para se chegar à solução }\end{array}$} \\
\hline \multirow{2}{*}{ 若 } & $\begin{array}{c}\text { Língua } \\
\text { Portuguesa / } \\
\text { Redação }\end{array}$ & Compressão de Texto & $\begin{array}{l}\text { Compactação de } \\
\text { Arquivos }\end{array}$ & $\begin{array}{c}9^{\circ} \text { e } 3^{\circ} \\
\text { anos }\end{array}$ & $\begin{array}{l}\text { Composição e decomposição para } \\
\text { tratamento de uma grande } \\
\text { quantidade de dados. Implica em } \\
\text { quebrar um problema em partes ou } \\
\text { etapas. }\end{array}$ \\
\hline & \multicolumn{5}{|c|}{$\begin{array}{l}\text { Foram discutidas as formas de retomada de texto sem excessiva repetição de palavras e a sua analogia com a } \\
\text { compactação de arquivos, que consiste no não armazenamento de dados iguais, para redução de tamanho do } \\
\text { arquivo. Buscou-se a similaridade entre a compactação de dados realizada pelo computador e os métodos de } \\
\text { compressão de texto, para se evitar repetições desnecessárias em sua construção, utilizando os textos "A } \\
\text { Aranha e a Jarra" (Bell et al. 2011, p. 24), "Amor é Fogo que Arde sem se Ver - Luís Vaz de Camões" e } \\
\text { "Felicidade Clandestina - Clarice Lispector". }\end{array}$} \\
\hline
\end{tabular}

\section{Análise dos Resultados: integração curricular a partir de uma concepção didática sócio-interacionista}

Com o objetivo de compreender melhor os participantes da intervenção que foi realizada, aplicou-se uma técnica de coleta de dados em pesquisas qualitativas, conhecida como grupo focal, que possibilitou investigar as impressões, críticas e sugestões dos professores participantes. Segundo Dias (2000, p. 3), "o objetivo central do grupo focal é identificar percepções, sentimentos, atitudes e ideias dos participantes a respeito de um determinado assunto, produto ou atividade [...]". E Ferraço (2007, p. 86), explica que "trabalhar com histórias narradas mostra-se como uma tentativa de dar visibilidade a esses sujeitos, afirmando-os como autoresautoras, também protagonistas dos nossos estudos.". Consequentemente, foi realizado uma análise prévia dessas falas, que foram transcritas de áudio para texto, articulando-as ao perfil formativo do professor, levantado por meio do questionário.

Vale a pena lembrar que em pesquisas qualitativas muitos sujeitos dificultam as análises sem ganho científico, portanto, consideramos a técnica de grupo focal com cruzamento de dados a partir da técnica de análise de conteúdo dado o número de sujeitos que temos. Ao aumentarmos a escala em estudos posteriores, tais técnicas podem não nos ser úteis, sendo preciso análises de natureza quantitativa ou híbrida.

$\mathrm{Na}$ aplicação do grupo focal com o objetivo de saber o que motivou esses professores a aceitarem as intervenções que ocorrem nas aulas, uma das primeiras perguntas foi: "Por que os senhores aceitaram o projeto aqui na escola? Você acreditam que esse tipo de ação é útil na formação dos estudantes?".

- Professora de Artes: "[...] a proposta que trouxeram, e a forma como eles iriam direcionar o meu conteúdo na quarta unidade, e era o que eu queria, um trabalho que envolvia a dança e ele trouxe isso para gente na prática [...] Como ele (fazendo referência ao moderador) falou: é uma dança que a gente vai fazer colocando a informática [...]" 
CBIE-LACLO 2015

Anais dos Workshops do IV Congresso Brasileiro de Informática na Educação (CBIE 2015)

- Professor de Educação Física: "[...] a escola não pode se fechar para nenhum tipo de conhecimento. Um conhecimento novo, um conhecimento que a gente não tinha, de como trabalhar a computação sem ter o computador. Então, só veio para agregar e não teve o porquê a escola, a gente, não aderir se é para agregar conhecimento? Então, gente foi ótimo. Não teria porque negar. [...]"

- Professora de Química: “[...] veio assim como a ferramenta para reforçar [...] os alunos hoje lidam mais com esses instrumentos melhor do que nós professores [...] importante a proposta, e veio como mais um elemento para você motivar o aluno, e facilitar a aprendizagem dele. [...] utilizando uma ferramenta que eles possuem muita habilidade. Então, com a utilização dessa ferramenta, eles desenvolveriam mais interesse deles, vamos assim dizer. Motivaria mais eles. E aí é mais fácil levar eles à aprendizagem. [...]"

Como podemos perceber no discurso dos quatro professores, por meio da análise discursiva, o que lhes motivou a aceitar participar das intervenções foi a existência de uma necessidade de compreensão do funcionamento da computação por parte dos alunos e deles também, pois alguns não dominam o uso das tecnologias digitais como alguns de seus estudantes. Essa atitude de reflexão sobre à prática é uma concordância com Freire (1996), ao explicar que o processo de ensinar e de aprender é uma atitude política de comprometimento com a transformação social.

Com o objetivo de saber se aquelas intervenções conseguiram aliar a prática com a teoria, perguntou-se: "Em relação ao conteúdo da disciplina de vocês. Vocês acharam que foi abordado? Foi proveitoso?".

- Professora-Coordenadora: "[...] a gente tem a certeza de que eles saem daqui como multiplicadores. Na realidade, qual é o grande êxito de um professor? - Quando o aluno sai da sala de aula que chega em casa e repassa o que ele aprendeu. [...] eu consegui enxergar lá na frente, eu não fiquei só naquela explicação. Eu falei: "poxa, mas isso aqui é fantástico, tanto que eu me interessei por computação, quando me aposentar, faltam 2 anos. Então estou pensando em fazer [...]"

- Professor de Educação Física: "[...] acho que os meninos precisam de mais encontros, até para poder trabalhar as dificuldades que tiveram nas atividades. Lá na sala a atividade foi motora, mas eles tiveram que usar uma lógica matemática, e eles tiveram bastante dificuldade matemática tem que ter contato frequente [...]. Porque para entender a lógica matemática eles precisam ter esse contato frequente, e eles não têm [...]"

- Professora de Química: “[...] na área de ciências da natureza quando vocês trabalharam aquela questão da conservação da massa, que eles trabalham lá por volta do $9^{\circ}$ e do $1^{o}$ ano, e aí a professora de biologia está trabalhando a cadeia alimentar. Então essa conservação aí, fazendo a relação com equilíbrio de equações, que às vezes o aluno não sabe pra quê aquilo serve e às vezes alguns alunos não aprendem, outros aprendem e aqueles que aprendem, aprendem mecanicamente [...] vocês atingiram sim o objetivo de estar utilizando a questão da informática com os conteúdos [...]"

Na pré-análise das falas, evidenciou-se ainda que esses professores possuem uma visão construtivista sócio-interacionista, onde os elementos sociais não podem ser dissociados da prática pedagógica, pois exercem influência sobre aqueles que eles estão ensinando. Tal interação mobilizou os alunos a pensarem novas formas de resolução de um problema, produzindo conhecimento. Dessa forma, acredita-se na ocorrência de 
CBIE-LACLO 2015

Anais dos Workshops do IV Congresso Brasileiro de Informática na Educação (CBIE 2015)

aprendizagem constante dos mesmos com o meio físico e social, construindo um novo conhecimento baseado nas experiências, deixando para trás, a forma tradicional de ensino.

Os discursos dos professores esclareceram que o objetivo de relacionar o conteúdo da disciplina com a CC foi alcançado. A satisfação por parte do estudante mostrando-se interessado, como expõe o professor, também foi alcançado. Além disso, as análises das falas mostraram que os professores das disciplinas conseguiram relacionar e compreender o diálogo entre os conteúdos de $\mathrm{CC}$ com os conteúdos abordados por eles e juntamente com os integrantes do projeto e os alunos, conseguiram construir um novo conhecimento.

Também foi possível identificar o desenvolvimento colaborativo, por meio de relações de troca, intervenção e aprendizagem, entre os estudantes, as(os) professoras(es), a universidade e a escola. Essas intervenções proporcionaram uma prática reflexiva, produzindo um processo inovador que consegue relacionar os saberes e traz condições para a aprendizagem de forma harmoniosa.

\section{Conclusão, Considerações e Desafios}

Com o desenvolvimento do projeto-piloto na escola, foram levantados os elementos iniciais para o estudo dos desafios e possibilidades da integração curricular da CC com as disciplinas da educação básica, como modo de desenvolvimento pedagógico do raciocínio computacional.

A partir das intervenções realizadas, iniciamos a concepção de uma abordagem didática de computação na escola baseada na recontextualização por hibridismo, levando para a escola novas práticas a partir das demandas que emanam das próprias vivências docentes do educador, levando em consideração a necessidade de cumprir as Diretrizes Curriculares Nacionais para a Educação Básica. Isso implica dizer que estamos tendo atenção à cultura local, buscando entender as nuances e variações das políticas educacionais que compõem o currículo de cada escola, almejando uma transformação social.

Atualmente o projeto está em fase de adaptação e transformação coletiva na forma de conceber o uso de novos métodos de ensino do raciocínio computacional. Logo, impulsionado e motivado pelo entusiasmo dos professores, o projeto está sendo ampliado e levado a outras duas escolas de ensino fundamental e/ou médio. E nesta nova etapa, temos algumas metas e desafios a cumprir. Uma dessas metas é mobilizar os professores e estudantes com novas atividades que fazem relação com uma ou mais disciplinas para que tenham subsídios suficientes para a sua atuação, favorecendo o processo de construção do conhecimento por parte dos seus alunos.

$\mathrm{Na}$ fase piloto não fizemos nenhum tipo de avaliação discente, mas espera-se em atividades futuras, a realização de análises em profundidade a partir do método de Análise de Conteúdo dos grupos focais e registros de observação participativa, envolvendo os principais atores desse processo. Pretendemos avaliar a qualidade e importância das ações, e verificar os níveis de aprendizado tanto dos conteúdos curriculares, quanto dos conteúdos de computação, realizando uma comparação entre o modo disciplinar e o modo interdisciplinar, tudo isso com base na construção das competências descritas nas Diretrizes Curriculares Nacionais para Educação Básica e no currículo escolar do Estado da Bahia.

A CC é uma área do conhecimento que não pode ficar fora do currículo escolar e utilizando a interdisciplinaridade como aliada, verificamos que podemos obter bons 
CBIE-LACLO 2015

Anais dos Workshops do IV Congresso Brasileiro de Informática na Educação (CBIE 2015)

resultados no âmbito educacional e assim ajudar a desenvolver uma educação de qualidade. Como proposta futura da continuidade desse projeto, o objetivo em participar ativamente das reuniões pedagógicas, onde é feita a construção do currículo e junto com os educadores, tornar o ensino do raciocínio computacional parte das atividades propostas para o ensino fundamental e médio.

\section{Agradecimentos}

À Coordenação de Aperfeiçoamento de Pessoal de Nível Superior (CAPES) e à Pró-Reitoria de Extensão da Universidade Federal da Bahia pelo apoio financeiro a esta intervenção.

\section{Referências}

Bell, T.; Alexander, J.; Freeman, I.; Grimley, M. (2009). Computer Science Unplugged: School students doing real computing without computers. The New Zealand Journal of Applied Computing and Information Technology, v.13, n.1. p. 20-29.

Bell, T.; Witten, I. H.; Fellows, M. (2011). Computer Science Unplugged: Ensinando ciência da computação sem o uso do computador. Tradução coordenada por Luciano Porto Barreto. Disponível em: <http://csunplugged.org/wpcontent/uploads/2014/12/CSUnpluggedTeachers-portuguese-brazil-feb-2011.pdf>.

Acessado: 24 de julho de 2015.

Brasil (2010). Sobre as Diretrizes Curriculares Nacionais para o Ensino Fundamental de 9 anos - Resolução CNE/CEB 7/2010. Ministério da Educação, Conselho Nacional de Educação. Câmara de Educação Básica. Diário Oficial da União, Brasília - DF, 15 de dezembro de 2010, Seção 1, p. 34.

Cassel, L. N. (2011). Interdisciplinary computing is the answer: now, what was the question? ACM Inroads, vol. 2, issue 1. p. 4-6.

Carvalho, M. L. B.; Chaimowicz, L.; Moro, M. M. (2013). Pensamento Computacional no Ensino Médio Mineiro. In: Anais do XIX Workshop de Informática na Escola (WIE). Campinas - SP.

Dias, C. A. (2000) Grupo focal: técnica de coleta de dados em pesquisas qualitativas. Informação \& Sociedade: Estudos, v. 10, n. 2.

Ferraço, C. E. (2007). Pesquisa em Cotidiano. Educação \& Sociedade, Campinas - SP, vol. 28, n. 98, p. 73-95, janeiro-abril.

Ferreira, A.C.C., Melhor, A., Barreto, J.S., Paiva, L.F, Matos, E. (2015). Experiência Prática Interdisciplinar do Raciocínio Computacional em Atividades de Computação Desplugada na Educação Básica. Anais do XXI Workshop de Informática na Escola (WIE). Alagoas SE.

Fortes, C. C. (2009). Interdisciplinaridade: origem, conceito e valor. Revista acadêmica Senac on-line. 6a ed. setembro-novembro. Disponível em: <http://www.pos.ajes.edu.br/arquivos/referencial_20120517101423.pdf>. Acessado em: 24 de julho de 2015.

França, R. S. et. al. (2014). A disseminação do pensamento computacional na educação básica: lições aprendidas com experiências de licenciandos em computação. In: Anais do 
CBIE-LACLO 2015

Anais dos Workshops do IV Congresso Brasileiro de Informática na Educação (CBIE 2015)

XXXIV Congresso da Sociedade Brasileira de Computação. XXII Workshop sobre Educação em Computação (WEI 2014). Brasília - DF.

Freire, P. (1996). Pedagogia da Autonomia: Saberes Necessários à Prática Educativa. Paz e Terra. São Paulo:

Howell L. et al, (2011). Computational thinking: modeling applied to the teaching and learning of english. In: Procs. of ACM-SE, Kennesaw, EUA. p. 48-53.

Japiassú, H.; Marcondes, D. (1993). Dicionário básico de filosofia. Zahar. Rio de Janeiro.

Jenkins, J. T.; Jerkins, J. A.; Stenger, C.L. (2012). A plan for immediate immersion of computational thinking into the high school math classroom through a partnership with the alabama math, science, and technology initiative. In: Procs. of ACM-SE, Tuscaloosa - EUA. p. 148-152.

Lopes, A. C. (2005), Recontextualização e Hibridismo. Currículo sem fronteiras, v. 5, n. 2, p. 50-64.

Matos, E. S. (2013) Integração curricular por meio da prática de ensino interdisciplinar em IHC. In: Anais do IV Workshop sobre o Ensino de IHC (WEIHC 2013). Simpósio Brasileiro sobre Fatores Humanos em Sistemas Computacionais. Manaus, AM. p. 25-30.

Matos, M. C.; Paiva, E. V. (2007). Hibridismo e Currículo: ambivalências e possibilidades Currículo sem Fronteiras, v.7, n.2.p.185-201.

Pinto, C. L. Q.; Rocha, C. R. C.; Vilarim, G. (2010). Desafios da Prática Interdisciplinar em Cursos de Ciência da Computação: a Experiência da UNIFESO. In: Anais do XXX Congresso da Sociedade Brasileira de Computação. XVIII Workshop sobre Educação em Computação (WEI 2010), Belo Horizonte - MG.

Ribeiro, L.; Nunes, D. J.; da Cruz, M. K.; Matos, E. S. (2013). Computational Thinking: Possibilities and Challenges. In: Procs. $2^{\text {nd }}$ Workshop-School on Theoretical Computer Science. Rio Grande, RS. p. 22-25.

Wing, J. M. (2006). Computational thinking. In: Communications of the ACM, vol. 49, n. 3. p. 33-35. 